\title{
MODE OF ATTACHMENT OF THE MONOGENEAN PROTOANCYLODISCOIDES MANSOURENSIS EL-NAGGAR 1987 \\ TO GILLS OF THE LONG FIN CATFISH CHRYSICHTHYS AURATUS, WITH REFERENCE TO HOST-PARASITE INTERFACE
}

\author{
Enayat S. Reda and Ahmed M. El-Naggar
}

Zoology Department. Faculty of Sciences. Mansoura University. Mansoura. Egypt

Key words: Chrysichthys cullatus. Protocincylodiscoides manscurensis. Monogenea, mode of attachment. local impacts, host response.

\begin{abstract}
$T$ he mode of attachment of the ancyrocephaline monogenean Proloancylodiscoides mansourensis to the gills of the long fin catfish Chrysichthys culratus has been investigated with reference to host-parasite interface. Light and scanning electron microscope observations revealed that the vast majority of worms secured themselves between two adjacent gill lamellae at the area opposite to the efferent or afferent side of the gill filament or at the middle area between the two sides, within the interlamellar space or channel. Frequently. the whole parasite was observed to hide behind the gill lamellae. The parasite preferred clinging to mucous cell-poor microhabitats such as proximal sector of the gill lamellae and avoided mucous cell-rich microhabitats such as the distal region of the gill filament and gill lamellae as well as the uppermost layer of interlamellar epithelium. The worm utilized one pair of large dorsal hamuli and another pair of comparatively small ventral hamuli to attach firmly on the host tissue. However, marginal hooklets had no role in attachment. The local histopathological impacts of the parasite on the gill tissues comprised compression and even tearing of the covering epithelium of the affected gill lamella, aggregation of blood corpuscles in the vicinity of haptoral attachment and change in the distribution pattern of different cell types of the affected gill lamella. A few number of lamellae became amorphous. The host response to Protoancylodiscoides infestation comprised gill tissue proliferation (hyperplasia), formation of sinus-like blood collection and occasional appearance of lymphocytes and/or mucus-producing cells in the vicinity of haptoral attachment. Ecological significance of the mode
\end{abstract}


of attachment and selection of highly protected or sheltered microhabitats and interaction between infested gill tissues and invading parasites are discussed in detail.

\section{INTRODUCTION}

The infestation course of a monogenean on a target host fish comprises three major processes, namely host finding, initial and terminal establishment on the preferred microhabitats and population growth accompanied by, or terminated in, stepwise dispersal among host individuals of the concurrent and/or subsequent host generation. Malmberg (1993) hypothesized that monogenean invasion of fish epithelium involves primarily an attraction of the parasite to the host and secondarily an ability of the host fish to combat the infection. Buchmann and Bresciani (1998) suggested that sensory mechanisms in ectoparasites are activated by certain molecules secreted by the host fish. Lyons (1969), Reuter (1987) and Halton et al. (1993) showed that monogeneans possess a range of neurotransmitters in their nervous system as well as sensory receptors such as tangoreceptors, chemoreceptors, rheoreceptors and/or mechanorecptors. El-Naggar and El-Tantawy (2002) assumed that monogeneans belonging to the gyrodactylids Gyrodacty/tus and Macrogyrodactylus probably have thermoreceptors as they survived a relatively wide thermal gradient staring at $1^{\circ} \mathrm{C}^{\prime}$ and reaching over $45^{\circ} \mathrm{C}$.

Monopisthocotylid monogeneans are epidermal browsers (feeders) where they graze on the epithelial cells by secreting proteases onto the surface that in turn disaggregate epidernal cells and allow the resulting suspension to be drawn up into the pharynx (see Sterud et al. 1998). Moreover, the vast majority of monogeneans make extensive use of haptoral sclerites, hooks and/or clamps to secure themselves partially to the host tissue (for example Llewellyn. 1958; Owen, 1963; El-Naggar et al., 2001) and this leads to local or focal impacts in light infestation and pronounced gross pathological abnormalities during heavy infestation (Wobeser ef al., 1976; \& Cone \& Odense, 1984). Johnsen and Jansen (1991) \& Ojha and Hughes (2001) demonstrated that heavy monogenean infestation leads to pronounced irritation and serious damage that has the potential to kill the stressed host fish. Moreover, ectoparasites usually cause an alteration (reduction or increase) in mucus production and mucous cell concentration in the host epidermis (Wells \& Cone, 
1990; Appleby et al. 1997; Buchmann and Uldal, 1997; Buclimann and Bresciani. 1998; \& Sterud et al. 1998). The rate of gas exchange (extraction of oxygen and elimination of carbon dioxide) seems likely to be correlated to the availability of numerous replicates of the active respiratory units and supportive pathways as well. In this respect. it may be hypothesized that the interference of a gill parasite to the respiratory function of the gills appears to comprise blocking of a number of the working respiratory units by preventing the water current to flush a definite sector of the microhabitat, impairing a working respiratory unit or disturbing the blood or water current pathways.

The long fin catfish Chrysichthys auratus is one of the most common edible fish species in the Nile Delta. The fish reach a marketable size within few months of breeding (Bishai and Khalil. 1997). El-Naggar and Reda (in print) reported on the infestation level of the ancyrocephaline monogenean Protouncylodiscoides mansourensis from the gills of $C$. auratus and recorded a higher percentage of infestation (97.27\%) and mean intensity $(20.79 \pm 22.03$ worms/infested fish) among feral host population. The present study aimed to throw light on the mode of attachment of $P$. mansourensis El-Naggar, 1987 to the gills of $C$. anratus, local histopathological impacts of the parasite on the gill tissues and host response to monogenean infestation under natural conditions. Better understanding of the ecology, ethology and pathology of $P$. mansourensis may provide an effective control measures against these parasites under laboratory or field conditions.

\section{MATERIALS AND METHOI:}

Specimens of the bottom dweller, “, ., 11 catfish Chrysichthys auratus were caught with special nets trum Danietta Branch of the River Nile during spring and summer months in 2002 and 2003. Live fish were transported to the laboratory in a plastic aquarium containing an amount of river water under good aeration. According to Whittington and Kearn (1991), there is a possibility that gill parasites may change their adhesive attitude in the short interval between the cessation of gill-ventilation when the host is killed and the detection of parasites on the excised gills. Therefore, it is recommended to preserve the specimens immediately in an appropriate fixative after their removal from the freshly killed host. In 
this respect, living fish were immediately immersed, prior to dissection and subsequent isolation of the gills, in an appropriate fixative since the vast majority of fish $(97.27 \%)$ were infested with $P$. mansourensis as reported by El-Naggar and Reda (in print).

To scan the surface features of gill microhabitats, alignment and mode of attachment of $P$. mansourensis during adhesive attitudes. living parasites on fresh gill tissues were selected. Freshly caught fishes were killed by severing the spinal cord and the gills were removed as quickly as possible, immersed in filtered river water and examined immediately under a stereomicroscope. Using appropriate dissecting instruments, small sectors of fresh gill tissue were isolated and then washed carefully in distilled water. Subsequently, they were fixed in $1 \%$ osmium tetroxide for about 30 minutes at $4 \pm 2^{\circ} \mathrm{C}$. immersed with cold sodium cacodylate buffer and post fixed in $2.5 \%$ glutraldehyde for about 2 hours at $4 \pm 2^{\circ} \mathrm{C}$. Preserved specimens were then washed repeatediy in cold sodium cacodylate buffer for about 2 days, dehydrated in an ascending gradient of either ethy] alcohol or acetone, critical point dried in a Samdri-PVT-3B drying unit. Then. the tissue was sputter coated with gold, using JEOL model JFC$1100 \mathrm{~F}$ sputtering device. Topographical features of the host, parasite and host-parasite interface were photographed under IEOL model ISM-5300 electron microscope.

Fresh sectors of non-infested (control) and Protoancylodiscoides-infested gill tissues were immediately fixed either in Bouin's, 10\% formaldehyde or Carnoy's mixture. The tissues were then dehydrated in an ascending series of alcohols and embedded in paraffin wax. Thereafter, gill tissues were processed for longitudinal sectioning at $5 \mu \mathrm{m}$ thickness and stained in Haematoxylin and Eosin. Stained sections were then dehydrated in alcohols, cleared in xylene and mounted in Canada balsam. Stained preparations were studied using Leitz Laborlux 20 research microscope provided with full automatic Camera.

\section{RESULTS}

\section{Description of the normal histology of gill microhabitats :}

The normal features of the gill filaments and gill lamellae of the long fin catfish C. curratus are shown in Figures 1-6. The axes of secondary lamellae lie at right angles to the long axis of the gill filament (Fig. 1). The gill lamellae were not found to extend to edges of the gill filament (Fig. 4). The gill filament possesses two rows of 
closely spaced gill lamellae over the surface of the filament (Fig. 1). Each gill filament is supported by a central cartilaginous ray surrounded by a tibrous coat (Fig. 1).

Each gill lamella comprises a basal or proximal sector and a distal or terminal one. Figure 2 shows that the covering epithelium at the proximal sector of the gill lamella is thin and more or less flattened. The endothelium of the gill lamella comprises a series of loosely packed pillar cells being reinforced by transverse strands of the basement membrane of the two opposite epithelia (Fig. 2). Blood corpuscles, mainly red blood cells, were observed to occupy the spaces between pillar cells (Figs. 2 and 5 ). Figure 3 shows that the covering epithelium at the distal sector of gill lamella is comparatively thick and multilayered. It could be also seen that the lamellar tissue is dominated by mucous cells and blood corpuscles. The blood capillaries are widened and overlapping (Fig. 3). A striking feature of the gills of $C:$ aturatus is that the mucous, goblet or mucusproducing cells are more concentrated over the distal sector of the gill lamellae (Fig. 3), distal region of the gill filament (Fig. 4) and uppermost layer of interlamellar epithelium (Figs. 5 and 6).

\section{Mode of attachment and important features of the haptor:}

The number of worms per gill filament ranged from one to five; however they were distributed between the two lamellar faces of the filament. The vast majority of Proloancylodiscoides worms secured themselves between two adjacent gill lamellae Figs. 7 and 8 at the area opposite to the efferent or afferent border of the gill filament or at the middle area between the two borders within the interlameilar space or channel. Frequently, gill lamellae attaining marked height were observed to conceal the whole worm. particularly when the parasite extends its body proper perpendicular to the haptor and parallel to the horizontal axis of the adjacent gill lamellae. It appears from Figures ( 7 and 8 ) that the marginal hooklets have no role in parasite attachment.

The haptor of $P$. mansourensis joins the body proper of the parasite and there is neither peduncle nor constriction demarcating the haptor from the body (Fig. 11). The haptor possesses a pair of obviously large dorsal hamuli and a second pair of comparatively small ventral hamuli, in addition to seven pairs of marginal hooklets. The latter showed heterogeneity in their size, with the anterior most pairs of marginal hooklets being the largest (Figs. $10 \& 11$ ). Each of 
the anterior most pairs (I \& VII) of the marginal hooklets measures 30 $\mu \mathrm{m}$. Each hamulus emerges from the haptor via a funnel-like projection originating from the tegument and bearing a terminal opening. The dorsal hamulus measures $76.89 \mu \mathrm{m}$ and is obviously larger than the ventral hamulus $(39.60 \mu \mathrm{m})$. The dorsal hamulus resembles a sickle and possesses a relatively long recurved blade (Figs. $9 \& 11$ ). It extends anteriorly within a horn-like tegumental sheath (Fig. 11). The dorsal hamulus blade measures $23.1 \mu \mathrm{m}$ and tapers distally to form a powerful needle. On the other hand, the ventral hamulus blade measures $9.9 \mu \mathrm{m}$ and tapers distally to form a powerful needle. Only the blades of the dorsal and ventral hamuli were seen penetrating the gill tissue, particularly the basal sector of the affected gill lamellae (Fig. 7).

Protoancylodiscoides worms preferred clinging to mucous cell-poor microhabitats such as the basal sector of gill lamella and avoided settling on mucous cell-rich microhabitats such as the dista] region of gill filament and gill lamellae as well as the efferent and afferent sides of gill filament and the uppermost layer of interlamellar epithelium.

\section{Histopathological impacts and host response :}

Only a small fraction of gill microbabitats of $C$. callatus was affected by the piercing or anchorage attitudes created by $P$. mansourensis. Obviously, the histopathological impacts were focal or local, being restricted in the vicinity of the haptoral attachment. These local histopathological impacts comprised compression and even tearing of the covering epithelium of the affected gill lamellae (Figs. 13. 14 and 15). Frequently, an aggregation of blood corpuscles underneath the covering epithelium of the gill lamella in the vicinity of haptoral attachment was recognized (Fig. 12). Such aggregation created a sinus-like blood collection. There was also a change in the distribution pattern of different cell types within the affected gill lamellae (Figs. 14 and 15). A few number of infested gill lamellae appeared amorphous (Fig. 15).

Host response to Profoancylodiscoides infestation were minor and comprised gill tissue proliferation (hyperplasia), formation of sinus-like blood collection, production of a few number of mucous cells and occasional appearance of lymphocytes in the vicinity of haptoral attachment (Figs. 12, 14 and 15). 


\section{DISCUSSION}

The present model showed that the monogenean $P$. mansourensis entirely occupies the interlamallar space or channel between two adjacent gill lamellae of a gill filament. Similar mode of attachment was demonstrated for Diclidophora esmarkii and $D$. luscae on the gills of Trisopterus minutus mimutus (Llewellyn et al., 1980), for Pseudodactylogyrus anguillae and P. bini on the gills of the immigrant European eel, Anguilla anguilla (El-Naggar and ElTantawy. 2001) and Cichlidogyrus species on the gills of Oreochromis niloticus niloticus (El-Naggar et al., 2001). The pattern of alignment and mode of attachment to the gill microhabitats varies from one monogenean species or group to another depending on the diversity of haptoral sclerites and magnitude of the hydrodynamic forces that are related to behavioural aspects of the host fish. Monogeneans exhibit a broad spectrum of adhesive attitudes including members clinging between two adjacent gill lamellae (Llewellyn et al., 1980), members sessile on the flat surface of gill filament (gill lamellae-free filament surface) (Whittington and Kearn, 1991) members holding their haptors longitudinally around the inner edge of gill filament (Whittington and Kearn, 1991) and those grasping several gill lamellae (see Kearn, 1998 and many references therein).

Ectoparasitic gill monogeneans appear to select more sheltered and highly protected microhabitats, with respect to the magnitude of hydrodynamic forces acting on the gills (see Wootten. 1974) and the risk of predation or exclusion by cohabitant organisms (see Paperna, 1964; Buchmann, 1989). Owen (1963) showed that the longitudinal axis of the bodies of all partner Diplozoon paradoxum were inclined toward the inter hemibranchial space of Rutilus rutilus. The author suggested that such alignment of the body clearly account for the region of fusion of each pair occurring in the inter hemibranchial space and this indicates that the adjacent gill filament afford some protection from the ventilating current to the region of fusion.

Similar selection for more sheltered and highly protected microhabitats was also reported for endoparasitic monogeneans. Cone et al. (1987) demonstrated that Enterogyrus species occupied the junction between the oesophagus and stomach of Pomacanthus paru. Entergyrus worms were observed to maintain their body axes directed 
perpendicular to longitudinal folds of the gut wall where they cling to host tissue principally by blades of the pair of large dorsal hamuli and apparently rely little on the action of small ventral hamuli and marginal hooklets. Cone et al. (1987) hypothesized that such adhesive attitude allows unrestricted movement when peristaltic waves move along the gut and the worm thereby maintains a stable footing and avoids the risk of being swept with the food items traveling across the alimentary tract.

The entry and exit points of the ventilating water current at each respiratory unit or interlanellar channel are formed respectively by the leading and trailing edges of the lamellae that correspond to the efferent and afferent ends of the lamellar circulation respectively (see Laurent, 1984). Ojha and Hughes (2001) found that the copepod $E$. bengalensis occupies a microhabitat towards the leading edge of the gill lamella. Such alignment may have the potential to induce great consequences for branchial respiration. The direction of water flow from the leading to trailing edge and the greater lamellar profile towards the former region of the interlamellar channels provide a firm anchorage for the parasite. During such attitude, the body of parasite blocks the entry points and disrupts laminar flow of water through the affected interlamellar spaces of gill sieve, and blood flowing through the lamellae blood channels will not be able to participate fully in gas exchange because of the lack of adequate partial oxygen pressure (Ojha and Hughes. 2001).

Haematoxylin and Eosin-stained preparations revealed that local histopathological features created by $P$. mumoswensis over the gill microhabitats comprised conpression and even tearing of the covering epithelium of the affected gill lamella, aggregation of blood corpuscles in the vicinity of haptoral attachment and change in the distribution pattern of different cell types of the affected gill lamella. However, a few number of the gill lamellae look amorphous. The worm utilized one pair of large dorsal hamuli and another pair of comparatively small ventral hamuli to attach firmly on the host tissue. However, marginal hooklets seem to play no role during attachment.

Similar local impacts were reportcd for other gill monogeneans infesting feral host populations (for example. ElNaggar et al., 2001; Ojha and Hughes, 2001). El-Naggar et cl. (2001) demonstrated that the dorsal and ventral hamuli of Cichlidogyrus species were inserted into the gill tissue of $O$. niloticus nilloicus with no role played by marginal hooklets in attachment. At the attachment sites, Cichlidogyrus worms created a more or less cup-shaped 
depression, injured the gill epithelium and caused slight vacuolation. degeneration of the gill lamellae and compression of the basement membrane (El-Naggar et al., 2001). In contrast, infestation under laboratory conditions as in aquaculture system seems to be more severe and highly intensive (for example, Molnar, 1980; Hoffman, 1981). Molnar (1980) showed that the death of the sheatfish Silurus glanis within 2-4 days of infection by the monogenean Ancylaliscoides vistulensis was due to the microtraumata inflicted on the cutaneous and gill epithelium cells by the hooks of the parasite.

Kearn (1999) hypothesized that monogenean marginal hooklets have evolved in response to the special challenges of attachment to fish epidermal cells. The uniform shapes and limited size range of marginal hooklets have probably been imposed by the unique and conservative cytoarchitecture of the superficial epithelial cells. The tiny marginal hooklets are firmly rooted in the so-called terminal web traced by $\alpha$-keratin tonofilaments (Kearn, 1999). The terminal seems to be sufficiently strong to resist tearing of the cell, so that mechanical damage is restricted to the small puncture where the point of the blade of a marginal hooklet enters (Kearn, 1999). Shinn et al. (1995) found that the marginal hooklets contain significant amounts of sulphur and may themselves be composed of $\alpha$-keratin tonofilaments, just similar to those of the host in which they are embedded. Spreading the load by employing many hooklets to provide multiple points of attachment to the host epidermal cells has proved to be a highly successful means of pinning a relatively small multicelluar parasite to the skin surface of the host fish. Such adhesive attitudes are sufficient for organisms dwelling the skin surface of the host fish that is relatively smooth or flattened.

On the other hand, gill microhabitats such as interlamellar epithelium, gill lamellae and gill filaments exhibit a relative heterogeneity with respect to their surface topography. Such microhabitats necessitate the possession of more adaptable adhesive mechanisms to conduct firm anchorage to an irregular fish epithelium. In this respect, the marginal hooklets of the posterior attachment organ of $P$. mansourensis are heterogeneous, with respect to the size and alignment within the haptoral planes. It is probable that marginal hooklets of a gill monogenean may be utilized for frequent and intermittent, temporary attachment to keep the established worm in a particular posture during consecutive entry-exit attitudes of the respiratory currents over the gill lamellae and 
interlamellar channels. A second probability is that the parasite may use marginal hooklets as alternative means of attachment prior to dislodgement and subsequent translocation to a replicate microhabitat.

Host response to infestation comprised gill tissue proliferation (hyperplasia), formation of sinus-like blood collection and occasional appearance of lymphocytes and mucus-producing cells in the vicinity of haptoral attachment. El-Naggar et al. (2001) suggested that gill tissue proliferation of the host fish in response 10 monogenean infestation may have three functions: (1) to entangle the intruder, monogenean worm via irritation, (2) to protect the underlying gill tissues against pathogenic organisms such as bacteria and viruses, and (3) to replace ruptured or compressed gill tissues by substitutive ones.

The present observations revealed that $P$. mansourensis preferred clinging to mucous cell-poor microhabitats such as the proximal sector of gill lamellae and avoided mucous cell-rich microhabitats such as the distal region of the gill filament and gill lamellae as well uppermost layer of interlamellar epithelium. This finding highlights the importance of mucus that may play a decisive role in microhabitat selection by $P$. mansourensis. Sterud et al. (1998) showed that goblet or mucus-producing cells differentiate from stem malpighian cells in the lower level of epidermis. maturing as they migrate to the surface. The authors hypothesized that any effect on maturation time of epidermal cells as a result of parasite grazing pressure may probably influence the rate at which goblet cells differentiate (Sterud et al.. 1998). Olson (1996) suggested that the interposition of a mucous film between the environment and gill epithelium is insulative in nature and that mucus may create a physical barrier to prevent mechanical abrasion or limil parasitic. bacterial, or viral access or an immunological barrier through an ability to secrete immunoglobulins. Ingram (1980) hypothesized that the continuous replacement of the epidermal mucus and the toxic effects of several components in the mucus create a barrier against infective agents. Moreover, mucus may decrease the coefficient of drag for water flow across the gill in a manner similar to its effects on the general body surface (Daniel, 1981).

Ojha and Hughes (2001) proved, using the diffusion index, that the respiratory efficiency of the gills of Wallago allu were negatively affected by the anchorage attitudes of the copepod and monogenean gill parasites. The authors observed that the anchorage of the copepod Ergasilus bengalensis towards the leading edge of 
interlamellar channels or spaces affects the-laminar flow of water through the gill sieve. They also demonstrated that about $35 \%$ of the water flow $\left(1.23 \times 10^{-3} \mathrm{~cm}^{3} / \mathrm{s}\right)$ and lamellar area $\left(15.41 \mathrm{~mm}^{2}\right)$ of an infested gill filament $(4.46 \mathrm{~mm})$ is affected by the copepod parasite $(1.59 \mathrm{~mm})$. Ojha and Hughes (2001) observed also that the monogenean parasite causes the fusion of the tips of gill filaments and distortion of lamellar epithelium. Though no data on the diffusing index have been calculated in the present study, it seems likely that an individual worm of $P$. mansourensis may block the entry point or disturb the traveling water current at the exit point between two adjacent gill lamellae, indicating a probable dysfunction of the respiratory unit in the vicinity of haptoral attachment. As the infestation intensity increases and reaches a maximum of 5 worms/gill filament, it is expected that at least five microhabitats (each comprising two gill lamellae and intermalellar epithelium. space or channel) will become functionless. Moreover, tearing of the covering epithelium of the affected gill lamiellae could make them vulnerable to viral and bacterial access. Dysfunction of a high proportion of the respiratory units could interfere with the metabolic pathways through a reduction in gas exchange potential and subsequent physiological disorders. However, aggregation of red blood corpuscles in the vicinity of haptoral attachment may neutralize the deleterious impacl of attachment by creating additional blood stores to replace blocked respiratory units.

\section{REFERENCES}

Appleby, C. ; Mo. T. A. and Aase. I. L. (1997). The Effect Of Gyrodactylus salaris (Monogenea) on the epidermis of Atlantic salmon, Salmo salar in the river Batnfjordselva. Norway. J. Parasitol., 83: 1173-1174.

Bishai, H. M. and Khalil, M. T. (1997). Freshwater Fishes Of Egypt. Publication of the National Biodiversity Unit No. 9, Department of Natural Protectorate, Egyptian Environmental Affairs Agency. 
Buchmann, K. and Bresciani. J. (1998). Microenvironment of Gyrodactylus derjavini on rainbow trout Oncorhynchus mykiss: association between mucous cell density in skin and site selection. Parasitol. Res.. 84: 17-24.

Buchmann, K. and Uldal, A. (1997). Gyrodactylus Derjavini infections in four salmonids: comparative host susceptibility and site selection of parasites. Dis. Aquat. Org.. 28:201-209.

Cone, D. K. ; Gratzek, J. B. and Hoffman, G. L. (1987). A study of Enterogyrus sp. (Monogenea) parasitizing the foregut of captive Pomacanthus parle (Pomacanthidae) in Georgia. Can. J. Zool., 65: 312-316.

Cone, D. K. and Odense, P. H. (1984). Pathology Of Five Species of Gyrodactylus Nordmann, 1832 (Monogenea). Can. J. Zool., 62: 1084-1088.

Daniel, T. L. (1981). Fish Mucus: In Situ Measurements Of Polymer drag reduction. Biol. Bull.. 160: 376-382.

El-Naggar, A. A. and El-Tantawy, S. A. (2001). Competitive coexistence and Microhabitat specialization of the monogenean gill parasites Pseudodactylogyrus anguillae. $P$. bini and Gyrodactylus anguillae on the immigrant European eel, Anguilla anguilla in Egypt. J. Union Arab Biol.. I6(A) Zoolorgy: 137-160.

El-Naggar, A. A. and El-Tantawy. S. A. (2002). Short-Term influence of water temperature, salinity or starvation on viability of the viviparous monogeneans Macrogyrodactylus: congolensis and Gyrodactylus alberti from the Nile catfish Clarias gariepinus. J. Egypt. Ger. Soc. Zool., 39(D): 29-49.

El-Naggar, A. A. and Reda, E. S. (2003). Infestation Level And spatial distribution of Protocincylodiscoides mansourensis El-Naggar 1987, a monogenean gill parasite from the long fin catfish Chrysichthys alratus Geoffroy, 1809 (in print). 
El-Naggar, M. M. (1987). Protoancylodiscoides Mansourensis N. sp. a monogenean gill parasite of the Egyptian freshwater fish Chrysichthys auratus Geoffroy 1809. Arab Gulf J. Scient. Res. Agric. Biol. Sci., B5 3: 441-454.

El-Naggar, M. M. ; Hagras, A. E. ; Ogawa, K. ; Hussein, A. B. and El-Naggar, A. A. (2001). Attachment Of ('ichlidhogrntws monogenean species to the gills of the Nile fish Oreochromis niloticus and their local pathological impact on them. I. Egypt. Ger. Soc. Zool., 35 (D): 143-155.

El-Tantawy, S. A. (2003). Scanning Electron Microscopy Of The tegument of Protoancylodiscoides mansourensis El-Naggar 1987, a monogenean gill parasite from the catfish Chrysichthys auratus. J. Egypt. Ger. Soc. Zool. (in print).

Halton, D. W. ; Maule, A. G. and Shaw, C. (1993). Neuronal mediators in monogenean parasites. Bull. Fr. Peche Piscic., 328: 82-104.

Hoffman, G. L. (1981). Helminthic Parasites. In: Principal diseases of farm-raised catfish. South Coop. Ser. Bull.. 225: 40-58.

Ingram, G. A. (1980). Substances involved in the natural resistance of fish to infection- a review. J. Fish Biol.. /6: 23-60.

Johnsen. B. O. and lensen, A. J. (1991). The Grodacty/us story in Norway. Aquacult., 98: 289-302.

Kearn, G. C. (1998). Parasitism and the platyhelminthes. Chapman and Hall.

Kearn, G. C. (1999). The survival of monogenean (platyhelminth) parasites on fish skin. Parasitology, 119: S57-S88.

Laurent. P. (1984). Gill internal morphology. In Fish Physiology X = (A): 73-183. Hoar, W. S. and Randall, D. J. (Eds). London: Academic Press. 
Lyons, K. M. (1969). Sense organs of monogenean skin parasites ending in a typical cilium. Parasitology, 59: 611-623.

Llewellyn, J, (1958). The adhesive mechanisms of monogenetic trematodes: The attachment of species of the diclidophoridae to the gills of gadoid tishes. J. Mar. Biol. Ass. U. K., 37: 67-79.

Llewellyn, J, ; Macdonald, S. and Green, J. E. (1980). Hostspecificity and speciation in diclidophoran (Monogenean) gill parasites of trisopteran (Gadoid) fishes at Plymouth. J. Mar. Biol. Ass. U. K.. 60): 73-79.

Malmberg, G. (1993). Gyrodactylidae and gyrodactylosis of salmonidae. Bull. Fr. Peche Piscic. 328: 5-46.

Molnar, K. (1980). A histological study of ancylodiscoides in the sheatfish (Silurus glanis). Helminthol., 17: 117-126.

Ojha, $J$. and Hughes. M. (2001). Effect of branchial parasites on the efficiency of the gills of a freshwater catfish, Wallago attu. J. Zool. Lond., 255: 125-129.

OIson, K. R. (1996). Scanning Electron Microscopy of the Fish Gill. In: J. S. Datta Munshi and H.M. Dutta eds.. Fish Morphology : Horizon of New Research. Balkema/Rotterdam/Brookfield.

Owen, I. L. (1963). The attachment of the monogenean Diplozoon parcidoxum to the gilis of Rutilus rutilus: L. I. Microhabitat and adhesive attitude. Parasitology, 53:455-461.

Reuter, M. (1987). Immunocytochemical demonstration of serotonin and neuropeptides in the nervous systen of Gyrodactylus salaris (Monogenea). Acta Zool., 68: 187193.

Shinn, A. P. ; Gibson, D. I. and Sommerville, C. (1995). A study of the composition of the sclerites of Gyrodactylus Nordmann 1832 (Monogenea) using $X$-ray elemental analysis. Int. $J$. Parasitol., 25: 797-805. 
Sterud, E. ; Harris, P. D. and Bakke, T. A. (1998). The influence of Gyrodactylus salaris Malmberg. 1957 (Monogenea) on the epidermis of Atlantic salmon, Salmo salar L., and brook trout, Salvelinus fontinalis (Mitchill): experimental studies. J. Fish Dis., 21: 257-263.

Wells, P. R. and Cone, D. K. (1990). Experimental studies on the effect of Gyrodactylus colemanensis and $G$. salmonis (Monogenea) on density of mucous cells in the epidermis of fry of Oncorhynchus mykiss. J. Fish Biol., 37: 599-603.

Whittington, I. D. and Kearn, G. C. (1991). The adhesive attitudes of some gill-parasitic capsalid monogeneans. .l. Helminthol.. 65: $280-285$.

Wobeser, G. ; Kratt, L. F. ; Snith, R. J. F. and Acompanado, G. (1976). Proliferative Branchiitis due to Tetraonchlss rauschi (Trematoda: Monogenea) in captive Arctic Grayling (Thymallus arcticus). J. Fish. Res. Board Can.. 33: 1817-1821. 


\section{LEGEND OF FIGURES}

Fig. 1. Light micrograph showing the normal histological features of an individual gill filament of ('hrysichthys comrams. Note that the gill filament is supported by a cartilaginous ray (c) surrounded by a fibrous coat (fc). Note also that the gill filament possesses two rows of gill lamellae (gl) and each gill lamella has a lamellar blood vessel (lbv). mc. Mucouis cells. Scale bar $=50 \mu \mathrm{m}$.

Fig. 2. Light micrograph showing the normal histological features of the proximal sector of the gill lanellae of ('. anrafus. Note that the covering epithelium (ce) is relatively thin and flattened. Note also that the pillar cells (pc) are separated by blood spaced filled with blood corpuscles. bc. Bloud capillary; lbv. lamellar blood vessel. Scale bar $=50 \mu \mathrm{m}$.

Fig. 3. Light micrograph showing the normal histological features of the distal sector of the gill lamellae. Note that the covering epithelium (ce) is thick and multilayered. Note also the dominance of mucous cells (mc) and blood corpuscles (bco). Scale bar $=50 \mu \mathrm{m}$.

Fig. 4. Light micrograph showing the distal area of the gill filament of C. auratus. Note that the mucus cells or goblet cells (mc) are intensive and occupy the periphery of the filament. Arrowhead points. non differentiated celis. Scale bar $=50$ $\mu \mathrm{m}$.

Fig. 5. Light micrograph showing the uppermost layer of the interlamellar epithelium among gill lamellae $(g l)$ of $c$. auratus. Note that the uppermost layer is rich in mucous or goblet cells $(\mathrm{mc})$. bco. Blood corpuscles; gl, gill lamella. Scale bar $=50 \mu \mathrm{m}$.

Fig. 6. Light micrograph showing constituent cells of the filament epithelium of $C$. auratus. Note the abundance of mucus or goblet cells (mc) and their terminal openings (o). Arrowhead points. non differentiated cells. Scale bar $=50$ $\mu \mathrm{m}$.

Fig. 7. Scanning electron micrograph showing a typical settlement of the monogenean Protoancylodiscoides mansourensis between two adjacent gill lamellae (gl) of an individual gill filament of $C$. curratus. Note that the parasite utilizes the dorsal hamulus (dha) and ventral hamulus (vha). h, Haptor: 
mh I, marginal hooklet I; mh VII, marginal hooklet VIl; r, root of the dorsal hamulus. Scale bar $=25 \mu \mathrm{m}$.

Fig. 8. Scanning electron micrograph showing attachment of $P$. mansourensis. Note that the marginal hooklet 1 (mh l) has no role in attachment. bp. Body proper of the parasite: gl. gill lamella. Scale bar $=10 \mu \mathrm{m}$.

Fig. 9. Magnified scanning electron micrograph showing the dorsat hamulus of the haptor of $P$. mansourensis. Note that the hamulus resembles a sickle and possesses a relatively straight shaft (sh) and sharp blade (b). Scale bar $=5 \mu \mathrm{m}$.

Fig. 10. Magnified scanning electron micrograph showing the first pair of marginal hooklets ( $\mathrm{mh} \mathrm{I}$ ) of the haptor of $P$. mansourensis. Note that the hooklet blade (hb) escapes from the haptoral tegument through a sieeve-like opening. Scale bar $=3 \mu \mathrm{m}$.

Fig. 11. Light micrograph showing the most common alignment of $P$. mansourensis on the attachment sites. The worm was dislodged from formalin fixed gill tissues. Note that the body proper of the worm (bp) lies perpendicular to the haptor (h). Note also that the dorsal hamulus (dha) is targe in size and extends anteriorly within a horn-like tegumental sheath (arrowhead points). db. Dorsal bar: mh 1. marginal hooklet I. Scale bar $=60 \mu \mathrm{m}$.

Fig. 12. Light micrograph showing attachment of $P$. mansourensis to the gills of ('. aurans. Note that the host develops a sinuslike blood collection (sb) in the vicinity of haptoral attachment of the worm. bp. Body proper of the parasite; gl, gill lamella. Scale bar $=150 \mu \mathrm{m}$.

Fig. 13. Light micrograph showing attachment of $P$. mansomenensis in the gills of $C$. auratus. Note the abnormal position of the gill lamellae (gl) and tearing of the covering epithelium (arrowhead points). bp. Body proper of the parasite; bco, blood corpuscles; h, haptor. Scale bar $=50 \mu \mathrm{m}$.

Fig. 14. Light micrograph showing attachment of $P$. mansourensis to the gills of $C$. auratus. Note the abnormal position of the gill lamellae (gl) and appearance of a few number of mucous cells on the covering epithelium (asterices). bp, Body proper of the parasite; bco, blood corpuscles inside the sinus; $h$, haptor. Scale bar $=50 \mu \mathrm{m}$. 
Fig. 15. Light micrograph showing attachment of $P$. mansotirensis to the gills of $C$. auratus. Note the compression of the lamellar epithelium (arrowhead points) and marked proliferation of the lamellar epithelium, appearance of mucous cells (asterices) and rarely lymphocytes (Ic) in the vicinity of haptoral attachment. b.p. Body proper of the parasite; bco, blood corpuscles are proliferative: mh $\mathrm{l}$. marginal hooklet l. Scale bar $=40 \mu \mathrm{m}$. 


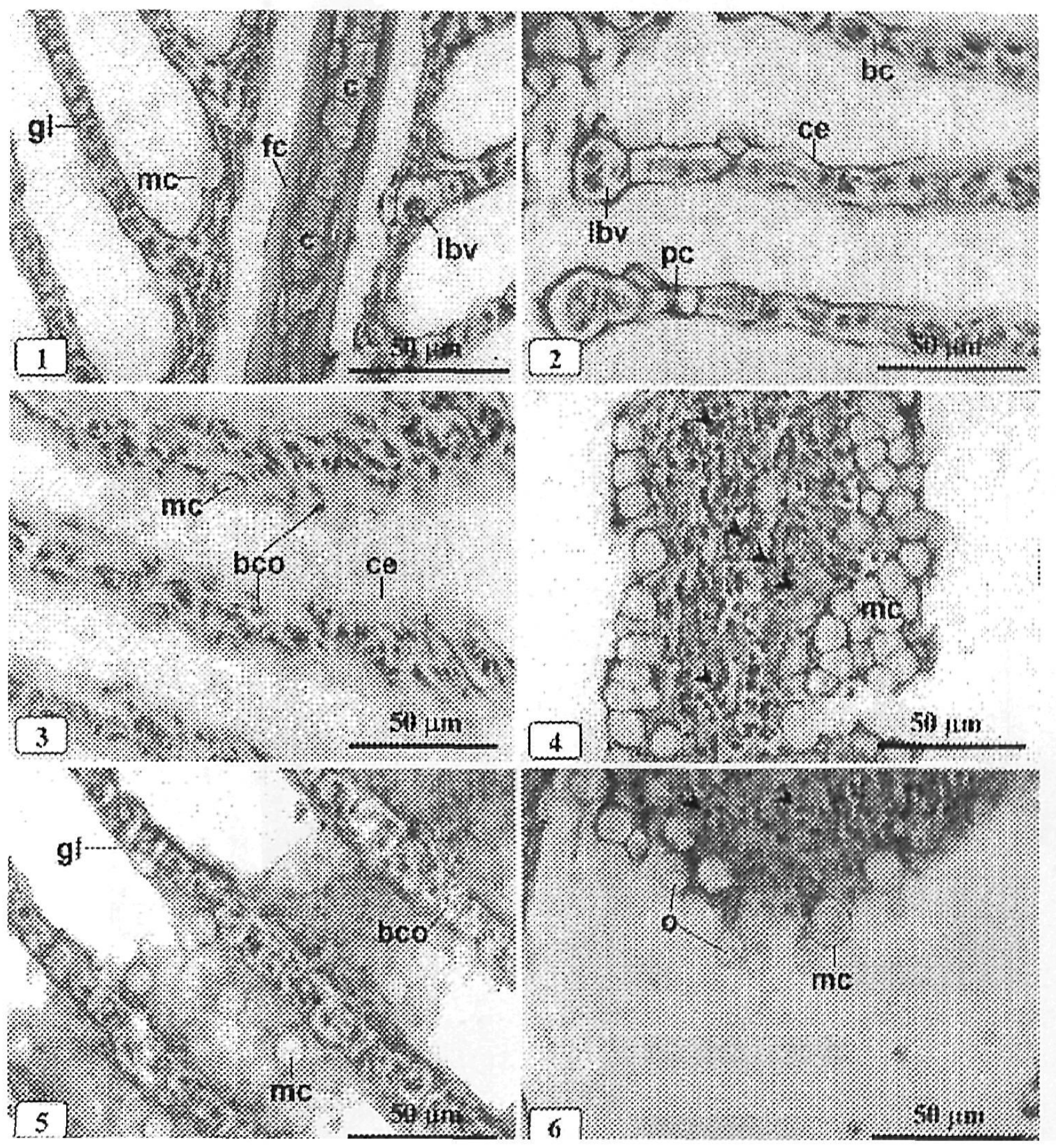




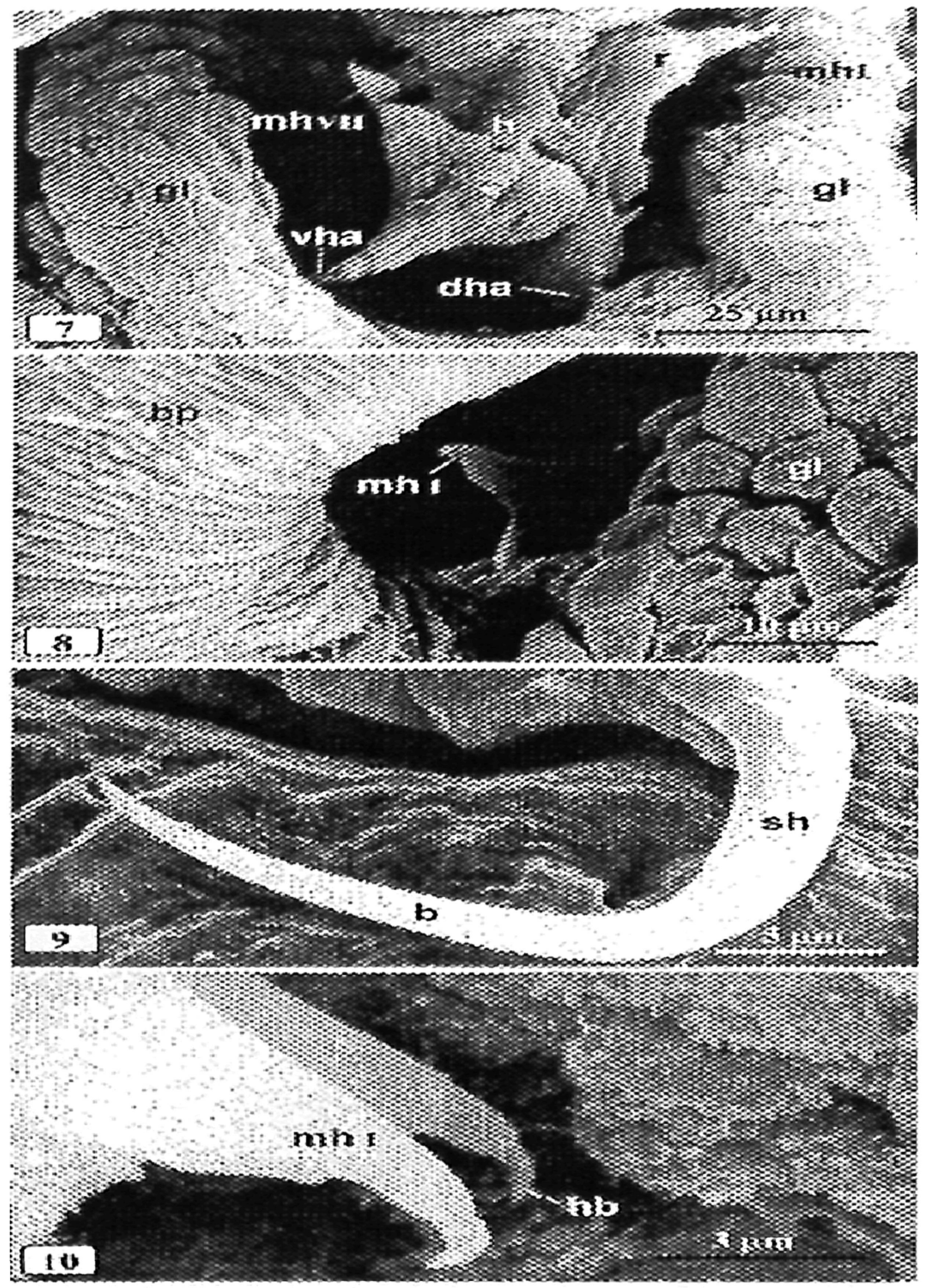




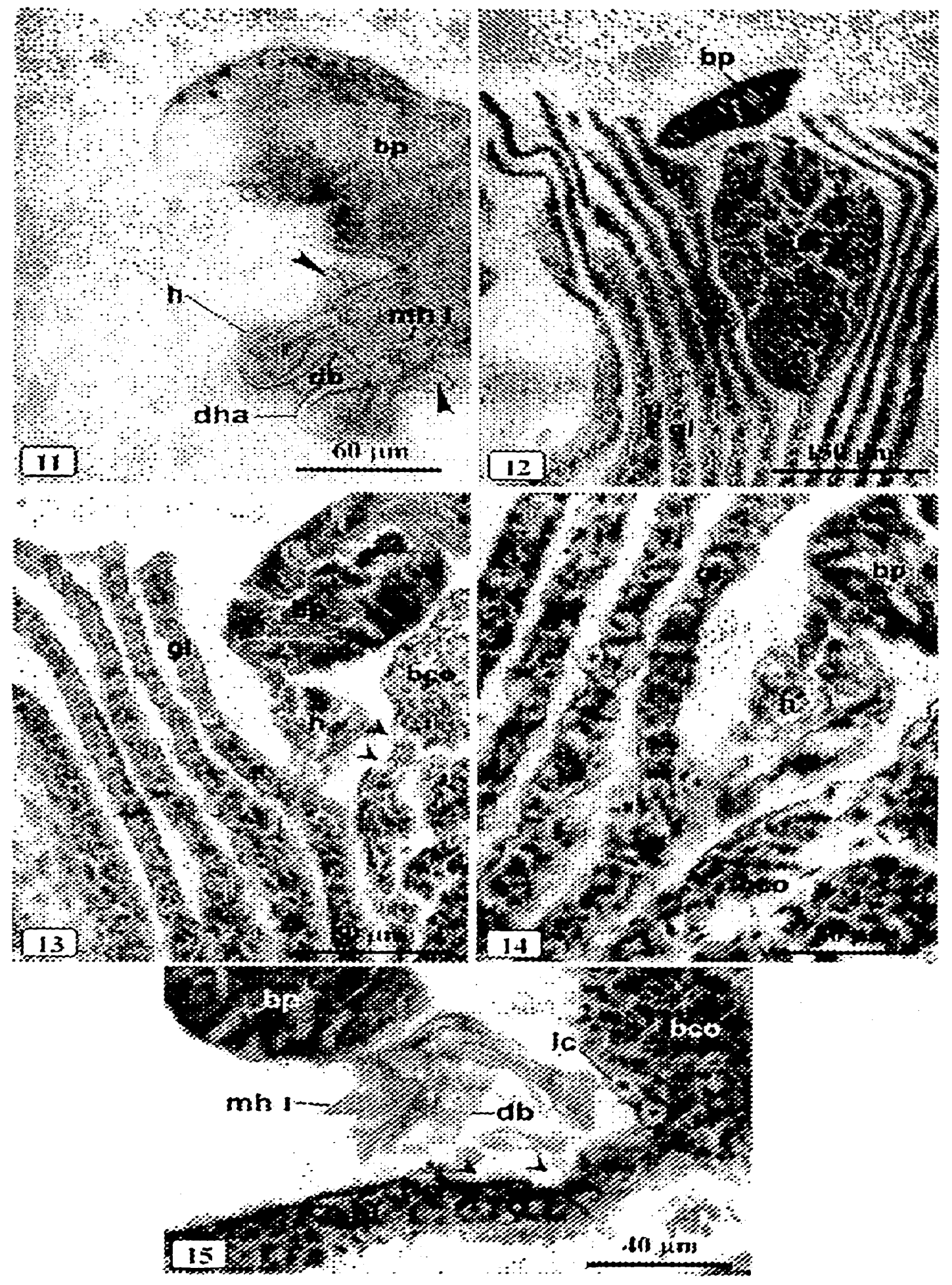

